\title{
Association between autistic traits and home nurture environment: A community-based study
}

\section{Sheng Qian}

Soochow University Medical College

\section{$\mathrm{Xin} \mathrm{Xu}$}

Soochow University Medical College

\section{Ying-quan Wang}

Soochow University Medical College

Jia-yu Li

Soochow University Medical College

Jing Li

Soochow University Medical College

Rui-xia Jia

Soochow University Medical College

Yong Xu ( $\nabla$ xuchildhealth@163.com )

\section{Research article}

Keywords: autistic traits; home nurture environment; parenting

Posted Date: April 7th, 2020

DOI: https://doi.org/10.21203/rs.3.rs-18754/v1

License: (c) (1) This work is licensed under a Creative Commons Attribution 4.0 International License.

Read Full License 


\section{Abstract}

Background: Increasing attention has been directed toward understanding the ways in which social environmental factors influence children's behavior, in physical and mental health domains. Autistic traits are continuously distributed in general population and children with autistic traits have great risk of additional mental diseases. However, no literature has demonstrated the relation between autistic traits and home nurture environment. Methods: Caregivers of 408 kindergarten children ( $68 \%$ male) were recruited to complete a series of survey measures in China. The measures used were the Clancy Autistic Behavior Scale and the Home Nurture Environment Scale. Multivariate logistic regression analysis was used to examine the associations. Results: Frequent language/cognition stimulation (aOR $0.520,95 \% \mathrm{Cl}$ 0.302-0.896), high level of parental warmth (aOR $0.596,95 \% \mathrm{Cl} 0.392-0.905)$ and high quality of physical living environment (aOR $0.332,95 \% \mathrm{Cl} 0.196-0.561)$ were the protective factors of autistic traits after controlling the confounding factors. Results were generally not moderated by the child's gender or birth order. Conclusions: These findings highlight the importance of high levels of home nurture environment for autistic traits and indicate that public health programs should focus on guidance of parents for developing more adequate parenting skills and favorable home nurture environment.

\section{Background}

Autistic traits are characterized by difficulties in interpreting social information, deficits in understanding those feelings of others, lessened desire to interact with others, repetitive and rigid behavior patterns.[1] Extensive evidence demonstrates that autistic traits are continuously distributed in general population.[2, 3]Assessing autistic traits in children is crucial because of the potential mental health implications they may have. Several studies have proved that children with a high level of autistic traits has a greater risk of additional mental diseases.[4] Social and communicative deficits characteristic of autistic traits have also been demonstrated to occur at elevated rates among children with other psychiatric conditions including mood disorders[5], anxiety [6], depression[7], conduct/oppositional defiant disorders[8] and even an early precursor of psychotic experiences.[9] In addition to this, Children with autistic traits have social interaction needs for peer problems [10-12] as well as higher risk for interpersonal victimization. [13]

In recent years, increasing attention has been directed toward understanding the ways in which social environmental factors influence children's behavior, in physical and mental health domains.[14, 15] Parental guidance and family support are critical to the development of children's psychological quality and health-related behaviors. [14, 16] Children living in chaotic households (e.g., lack of organization, confusing and unpredictable schedules and loud noise) reveal more behavioral problems. [17] Thus, to the extent that parents with low quality parenting would lead to poor nurture environment, the child may also exhibit poorer mental and physical health.[18]

However, most studies are limited by a focus on specific domains of autistic traits (e.g., theory of mind) or by the limited areas of parenting styles. On the best of our knowledge, as yet, no literature has demonstrated the relation between autistic traits and home nurture environment. In China, there are 
concerns that the concurrence of the only-child policy and the tradition of respect for elders, filial piety and obedience would result in increased stress of children, which may lead to behavior problems. $[19,20]$ Thus, it has practical significance to carry out relevant research. Given this, the aim of this study was to investigate the association between children aged 3 to 6 years with autistic traits and their home nurture environmental factors in China.

\section{Methods}

\subsection{Participants and data collection}

We identified the positive screening result of Clancy Autism Behavior Scale[21] as the specific outcome. We run the test on the 2600 children age 3- 6 years from 6 kindergartens in Taicang District, Suzhou from May to June, 2019. If the result turned to positive, then we consider the child was with autistic trait. Then we used Home Nurture Environment Scale[22] to evaluate the circumstance of the home nurture environment. Meanwhile, demographic data was collected including gender, parental education level, birth order, separation period with mother and the primary caregiver. Children with pre mental disease and acute medical illness were excluded from the study. The primary caregiver of children gave informed consent prior to entry into the study first and then fulfilled the questionnaires. The study adhered to the Declaration of Helsinki and ethics approval was obtained from the Institutional Review Board of Soochow University. Ultimately, a total of 204 children who satisfied the inclusion and exclusion criteria formed the screening positive group. (Fig. 1 shows) In consideration of gender as a proven risk factor[23] as well as birth year and birth order as clinical confounding factors, the 204 children was matched to controls on the three factors mentioned above. The controls were normally developing children from kindergartens aged from 3-6 years in Taicang District, Suzhou. For data quality control, $5 \%$ of the questionnaires were randomly selected and were rechecked, and on average, these showed $97 \%(73 / 75)$ consistency with previously answers.

\subsection{Measures}

\subsubsection{Autistic traits}

Autistic traits were measured with the Clancy Autism Behavior Scale (CABS)[21]. It is a validated tool for assessing the risk of autistic traits in screening toddlers aged between 2 to 6 years which widely used in mainland China.[24, 25] It contains 14 items with each item rating three frequency levels, including "Never" (score of 0 ) "Occasionally" (score of 1) and "Often" (score of 2). Scores on the CABS are usually divided into three groups according to cut-off points of 14 and 21 . For the reason that the scale is consisted of 14 kinds of typical autistic behaviors, using this scale to identify autistic traits is reasonable. If a child scores equal to or higher than 14 , the child is considered as a case with autistic traits. One previous study reported a sensitivity of $88 \%$ and specificity of $82 \%$ about the performance of CABS.[26]

\subsubsection{Home Nurture Environment}


The $3 \sim 6$ Years Child Home Nurture Environment Scale[22] is designed based on Chinese culture background, which consist of 53 items in order to measure diverse variables associated with parenting behaviors and living environment. Each item is divided by 5 frequency rates (hardly ever, seldom, occasionally, frequently and normally) to 5 points $(1,2,3,4$ and 5$)$. The total rewards will be calculated by these points and will rank to 3 levels (good, average and unsatisfactory). The good level is higher than $85 \%$, the average level is defined by $15 \%-85 \%$ and the percentage below 15 is unsatisfactory. The scale included six factors: language/cognition stimulation, parental warmth, social adaptation/self care, variety of actives and games, neglect/intervention/punishment and physical living environment. It should be completed by caregivers. The reliability coefficients of the scale indicated by split-half correlation (0.871) and Cronbach alpha (0.930) are satisfactorily high.

\subsection{Statistical analysis}

Initial unadjusted analyses were performed for all demographic and nurture environmental variables to identify those significantly associated with autistic traits. Categorical variables were presented as frequencies and percentages and conducted by chi-square test. Continuous variables were analyzed by independent $\mathrm{t}$-test and presented as mean and standard deviation. Variables that were clinically relevant or that showed a univariate relationship with outcome were entered into multivariate logistic regression model. Multivariate logistic regression model with adjusted odds ratio was performed to predict nurture environmental factors associated with autistic traits. P-values were calculated to three decimal places and $\mathrm{P}<0.05$ was the criterion for significance. All analysis was performed using SPSS, Version22. (SPSS Inc, Chicago, USA)

\section{Results}

All of children were $3-6$ years old and of Han ethnicity. Among the 204 cases and 204 controls, there were 140 male and 64 female children for a sex ratio of 2.02:1, reflecting the male preponderance for the autistic trait. The mean age of autistic children was $4.65 \pm 1.111$ years, and mean age of normal children was $4.75 \pm 1.109$ years. $(t=0.981, P=0.327)$ Table 1 displays the mean scores of home nurture environment scale for each level. Based on the result, there was no unsatisfactory level among six levels. 
Table 1

Scores of Home Nurture Environment Scale for each level

\begin{tabular}{|lll|}
\hline home nurture environmental factors & $\begin{array}{l}\text { screening positive group } \\
\text { (mean } \pm \text { SD) }\end{array}$ & $\begin{array}{c}\text { control group } \\
\text { (mean } \pm \text { SD) }\end{array}$ \\
\hline language/cognition stimulation & & $43.66 \pm 5.065$ \\
\hline average level & $43.39 \pm 5.29$ & $53.94 \pm 2.351$ \\
\hline good level & $52.82 \pm 1.701$ & \\
\hline parental warmth & & $30.19 \pm 3.532$ \\
\hline average level & $30.03 \pm 3.174$ & $37.04 \pm 2.004$ \\
\hline good level & $36.33 \pm 1.772$ & $40.61 \pm 4.005$ \\
\hline social adaptation/self care & & $49.24 \pm 2.375$ \\
\hline average level & $39.24 \pm 2.375$ & \\
\hline good level & $46.69 \pm 2.302$ & $28.30 \pm 5.69$ \\
\hline neglect/intervention/punishment & & $47.50 \pm 0.707$ \\
\hline average level & $26.09 \pm 6.906$ & \\
\hline good level & $47.50 \pm 0.707$ & $19.89 \pm 2.019$ \\
\hline variety of actives and games & & $25.35 \pm 2.122$ \\
\hline average level & $19.66 \pm 1.919$ & \\
\hline good level & $24.97 \pm 1.82$ & \\
\hline physical living environment & & \\
\hline average level & $17.17 \pm 2.61$ & \\
\hline good level & & \\
\hline
\end{tabular}

Table 2 presents crude odds ratios from univariate analyses. Father completed primary school or below was associated with increased risk for autistic traits. Decreased risks of autistic traits were found in parents as primary caregiver, high level of language/ cognition stimulation, parental warmth and physical living environment and general quality of home nurture environment $(P<0.05)$. However, maternal educational level, separation period longer than 6 months, frequent neglect/intervention/punishment and insufficient opportunities of social adaptation/self care and variety of actives and games were not significantly different between case and control groups. 
Table 2

Distributions, unadjusted $\mathrm{OR}$ and $95 \% \mathrm{Cl}$ for demographic and home nurture environmental factors

\begin{tabular}{|c|c|c|c|c|c|}
\hline & $\begin{array}{l}\text { Screening } \\
\text { positive group }\end{array}$ & $\begin{array}{l}\text { Control } \\
\text { group }\end{array}$ & OR & $95 \% \mathrm{Cl}$ & $\begin{array}{l}\mathrm{p}- \\
\text { value }\end{array}$ \\
\hline & $n(\%)$ & $\mathrm{n}(\%)$ & & & \\
\hline \multicolumn{6}{|l|}{ Paternal education level } \\
\hline master and above & $11(5.4)$ & $6(2.9)$ & - & & \\
\hline collage & $30(14.7)$ & $26(12.7)$ & 1.589 & $\begin{array}{l}0.516 \\
4.893\end{array}$ & 0.42 \\
\hline undergraduate & $108(52.9)$ & $86(42.2)$ & 1.46 & $\begin{array}{l}0.519 \\
4.107\end{array}$ & 0.473 \\
\hline middle school or below & $55(27)$ & $86(42.2)$ & 2.867 & $\begin{array}{l}1.002 \\
8.198\end{array}$ & $0.049 *$ \\
\hline \multicolumn{6}{|l|}{ maternal education level } \\
\hline master and above & $7(3.4)$ & $7(3.4)$ & - & & \\
\hline collage & $37(18.1)$ & $13(6.4)$ & 0.351 & $\begin{array}{l}0.103 \\
1.194\end{array}$ & 0.094 \\
\hline undergraduate & $93(45.6)$ & $94(46.1)$ & 1.011 & $0.341,2.995$ & 0.985 \\
\hline middle school or below & $67(32.8)$ & $90(44.1)$ & 1.343 & $0.45,4.013$ & 0.597 \\
\hline \multicolumn{6}{|l|}{ separation period } \\
\hline longer than 6 months & 184(90.2) & 188(92.2) & - & & \\
\hline less than 6 months & $20(9.8)$ & $16(7.8)$ & 0.783 & $\begin{array}{l}0.393 \\
1.558\end{array}$ & 0.486 \\
\hline \multicolumn{6}{|l|}{ primary caregiver } \\
\hline grandparents & $63(30.9)$ & $32(15.7)$ & - & & \\
\hline parents & $141(69.1)$ & 172(84.3) & 0.416 & $\begin{array}{l}0.258 \\
0.673\end{array}$ & $<.001 *$ \\
\hline \multicolumn{6}{|c|}{ language/cognition stimulation } \\
\hline average level & $176(86.3)$ & $154(75.5)$ & - & & \\
\hline high level & $28(13.7)$ & $50(24.5)$ & 0.49 & $\begin{array}{l}0.294 \\
0.817\end{array}$ & 0.006 * \\
\hline
\end{tabular}

*Significant $(P<0.05)$ 


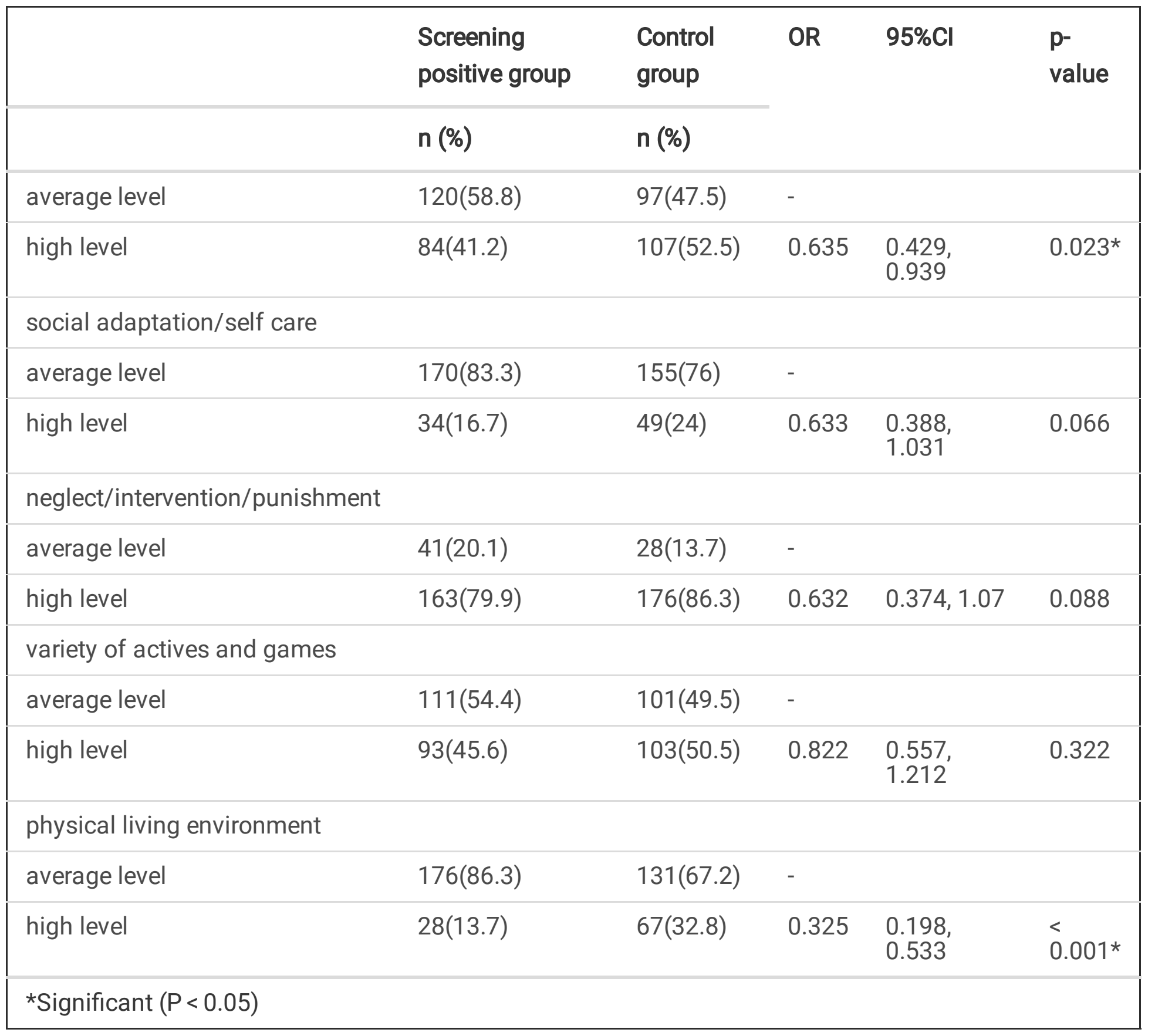

On multivariate regression analyses(Table 3), adjusting for familial characteristics(birth year, gender, birth order, parental educational level, primary caregiver and separation period) showed frequent language/cognition stimulation(aOR $0.520,95 \% \mathrm{Cl} 0.302-0.896$ ), favorable parental warmth(aOR 0.596 , $95 \% \mathrm{Cl} 0.392-0.905)$, pleasant physical living environment(aOR $0.332,95 \% \mathrm{Cl} 0.196-0.561)$ were associated with decreased odds of autistic traits. 
Table 3

Multiple-factor logistic regression analysis of autistic traits

\begin{tabular}{|llll|}
\hline home nurture environmental factors & aOR & $95 \% \mathrm{Cl}$ & p-value \\
\hline language/cognition stimulation (high level vs. average level) & 0.52 & $0.302,0.896$ & $0.019^{*}$ \\
\hline parental warmth (high level vs. average level) & 0.596 & $0.392,0.905$ & $0.015^{\star}$ \\
\hline social/adaptation self-care (high level vs. average level) & 0.717 & 0.405 .1 .208 & 0.211 \\
\hline neglect/intervention/punishment (high level vs. average level) & 0.635 & $0.364,1.106$ & 0.109 \\
\hline variety of actives and games (high level vs. average level) & 0.729 & $0.479,1.111$ & 0.142 \\
\hline physical living environment (high level vs. average level) & 0.332 & $0.196,0.954$ & $0.03^{*}$ \\
\hline *Significant $(P<0.05)$ & & & \\
\hline
\end{tabular}

Adjusted for: birth year, gender, birth order, parental educational level, primary caregiver and separation period

\section{Discussion}

We have conducted a rigorous community-based cross-sectional study, frequency-matched on gender, birth year and birth order to investigate the home nurture environmental factors for autistic traits in China. Overall, the results from the study suggested that poor home nurture environment, including insufficient language/cognition stimulation, undesirable parental warmth and poor physical living environment may place preschool children at a great risk for autistic traits. We will discuss each of these findings in turn and address the implications of these findings.

We found that frequent language/cognition stimulation, which means the quality of verbal and cognitive information a caregiver provides to a child was significantly associated with autistic traits. In other words, children with higher levels of autistic traits reported by caregivers had more difficulty on language interaction. The variability in child language in the early years is well-established.[27] Positive characteristics such as high maternal vocabulary level[27] and high socio-economic status[28] have advantageous impact on children's language and cognitive development. One previous research also demonstrated that poorer child language development predicted more autistic traits.[29] It is hypothesized that the identified association between autistic traits and language and cognitive stimulation may be explained by two key pathways. Firstly, there is a relationship between early language and later autistic traits, which is comparatively to the interaction with caregivers.[30] Therefore, caregivers did not give children enough response and less opportunities on verbal and cognitive information, children with autistic traits themselves has deficiency on capability for self-explanation and communication, and as a result, the symptom would also be more obvious. Alternatively, it has been reported that the shared genetic influences of children and caregivers may be responsible for the overlap 
in linkage signals reported in molecular genetic studies of language skills and autistic traits.[31, 32] Caregivers themselves had defect on communication skills, and therefore decrease the stimulation of language at home environment. Although this finding need to be replicated before any firm conclusions can be mad, it raises the possibility that early interventions in terms of language and cognitive skills by caregivers may reduce the occurrence of autistic traits.

Previous research has demonstrated parental warmth an indicator of parents' love and acceptance of the child[33] which was associated with children's better mental health and psychological adjustment, as well as lower levels of child behavior problems.[34] Studies examining warm affect, positive cooperation and communication showed negative associations with conduct problems and high levels of emotional symptoms.[35, 36] In our study, we found parental warmth a protective factor for autistic traits. Generally speaking, if a child did not experience consistent warmth from a parent, his own positive emotional responsiveness to the parent might decrease. Likewise, if a parent found that their attempts at warmth were not reciprocated, the frequency of their displays of warmth would also decrease over time.[35] Preschool children with high levels of autistic trait were preceded by early manifested ASD-like problems in infancy and toddlerhood.[37] Thus, favorable parental warmth and considerate care in early childhood are needed in an attempt to diminish further derailment of the child's behavior and development, and to prevent the autistic traits or related externalizing problems. However, it is yet to be established whether interventions targeting particular aspects of parental warmth or other parenting behaviors can be effective in driving more change in children with high levels autistic traits or if such interventions can directly reduce autistic traits, which are both questions we hope to examine in future studies.

The home physical environment not only affects individual child well-being, but also is an important pathway through which socio-economic inequalities create child health and developmental disparities. Unstable home physical environment has negative effects on children's health and development.[38] One possible reason proposed for the negative effects of poor physical environments on child behavior problem is through increased exposure to stress. $[39,40]$ Biological changes are likely to occur if the body is exposed to chronic stress (repeated stress response over time), resulting in dysfunction of the neuroendocrine and immune systems. These systems might be particularly sensitive during the formative years of childhood.[41] Dysfunction of children's neuroendocrine, in turn, is associated with cognitive[42] and socio-emotional [38]outcomes. Children with autistic traits have lower neuropsychological performance [43] and impairment in social function.[11,44] And as a result, terrible home physical environment may make their symptoms more apparent.

All of these findings should be interpreted in the context of several study limitations. First, there are clear limitations with using a tool of this type to measure home nurture environment. It relies on the observation and perceptions of parents, who may not be entirely objective. Second, because we did not assess other emotional or behavioral problems, we could not rule out the possibilities that other comorbid conditions may have contributed to the significant associations between autistic trait and home nurture environment reported in this study. In addition, the study was limited to only six schools in one city, with obvious issues of representativeness for the wider population. 


\section{Conclusions}

In conclusion, findings revealed that high levels of autistic traits were related to poor home nurture environment. Furthermore, frequent language and cognition stimulation, favorable parental warmth and pleasant home physical environment were the protective factors for autistic traits. Taken together, the current study extends the previous research on potential influences in terms of parenting which is relevant to autistic traits, and highlights the importance of home nurture environment. Meanwhile, it would indicate that public health programs should also focus on guidance of parents for developing more adequate parenting skills and favorable home nurture environment.

\section{Declarations}

Ethics approval and consent to participate

The study adhered to the Declaration of Helsinki and ethics approval was obtained from the Institutional Review Board of Soochow University. The participants gave informed consent prior to entry into the study first and then fulfilled the questionnaires.

Consent for publication

Not applicable.

Availability of data and materials

All data generated or analyzed during this study are included in this published article.

Competing interests:

We declare that we have no financial and personal relationships with other people or organizations that can inappropriately influence our work, there is no professional or other personal interest of any nature or kind in any product, service and/or company that could be construed as influencing the position presented in, or the review of.

\section{References}

1.

Constantino JN, Todd RD. Autistic traits in the general population: a twin study. Arch Gen Psychiatry. 2003;60(5):524-30.

2.

Constantino JN, Charman T. Diagnosis of autism spectrum disorder: reconciling the syndrome, its diverse origins, and variation in expression. Lancet Neurol. 2016;15(3):279-91.

3.

Haraguchi H, Stickley A, Saito A, Takahashi H, Kamio Y. Stability of Autistic Traits from 5 to 8 Years of Age Among Children in the General Population. J Autism Dev Disord. 2019;49(1):324-34. 
4.

Xu W, Fu Z, Wang J, Zhang Y. Relationship between autistic traits and hoarding in a large non-clinical Chinese sample: mediating effect of anxiety and depression. Psychological reports. 2015;116(1):23-32. 5.

Pine E, Luby J, Abbacchi A, Constantino JN. Quantitative assessment of autistic symptomatology in preschoolers. Autism: the international journal of research practice. 2006;10(4):344-52.

6.

Pine DS, Guyer AE, Goldwin M, Towbin KA, Leibenluft E. Autism spectrum disorder scale scores in pediatric mood and anxiety disorders. J Am Acad Child Adolesc Psychiatry. 2008;47(6):652-61. 7.

Lundstrom S, Chang Z, Kerekes N, Gumpert CH, Rastam M, Gillberg C, Lichtenstein P, Anckarsater H. Autistic-like traits and their association with mental health problems in two nationwide twin cohorts of children and adults. Psychological medicine. 2011;41(11):2423-33.

8.

Schoorl J, van Rijn S, de Wied M, van Goozen S, Swaab H. Emotion Regulation Difficulties in Boys with Oppositional Defiant Disorder/Conduct Disorder and the Relation with Comorbid Autism Traits and Attention Deficit Traits. PloS one. 2016;11(7):e0159323.

9.

Bevan Jones R, Thapar A, Lewis G, Zammit S. The association between early autistic traits and psychotic experiences in adolescence. Schizophr Res. 2012;135(1-3):164-9.

10.

Skuse DH, Mandy W, Steer C, Miller LL, Goodman R, Lawrence K, Emond A, Golding J. Social communication competence and functional adaptation in a general population of children: preliminary evidence for sex-by-verbal IQ differential risk. J Am Acad Child Adolesc Psychiatry. 2009;48(2):128-37. 11.

Hsiao MN, Tseng WL, Huang HY, Gau SS. Effects of autistic traits on social and school adjustment in children and adolescents: the moderating roles of age and gender. Res Dev Disabil. 2013;34(1):254-65. 12.

Chien YL, Tu EN, Gau SS. School Functions in Unaffected Siblings of Youths with Autism Spectrum Disorders. J Autism Dev Disord. 2017;47(10):3059-71.

13.

Roberts AL, Koenen KC, Lyall K, Robinson EB, Weisskopf MG. Association of autistic traits in adulthood with childhood abuse, interpersonal victimization, and posttraumatic stress. Child Abuse Negl. 2015;45:135-42.

14.

Klemfuss JZ, Wallin AR, Quas JA. Attachment, household chaos, and children's health. Families systems health: the journal of collaborative family healthcare. 2018;36(3):303-14.

15.

Evans GW. Child development and the physical environment. Ann Rev Psychol. 2006;57:423-51. 16. 
Philips N, Sioen I, Michels N, Sleddens E, De Henauw S. The influence of parenting style on health related behavior of children: findings from the ChiBS study. Int J Behav Nutr Phys Act. 2014;11:95-5.

17.

Vernon-Feagans L, Garrett-Peters P, Willoughby M, Mills-Koonce R. Chaos, Poverty, and Parenting: Predictors of Early Language Development. Early childhood research quarterly. 2012;27(3):339-51. 18.

Mills-Koonce WR, Willoughby MT, Garrett-Peters P, Wagner N, Vernon-Feagans L. The interplay among socioeconomic status, household chaos, and parenting in the prediction of child conduct problems and callous-unemotional behaviors. Dev Psychopathol. 2016;28(3):757-71.

19.

Shen J, Yuan BJ. Moral values of only and sibling children in mainland China. J Psychol. 1999;133(1):115-24.

20.

Hesketh T, Zheng Y, Jun YX, Xing ZW, Dong ZX, Lu L. Behaviour problems in Chinese primary school children. Soc Psychiatry Psychiatr Epidemiol. 2011;46(8):733-41.

21.

Clancy H, Dugdale A, Rendle-Short J. The diagnosis of infantile autism. Dev Med Child Neurol. 1969;11(4):432-42.

22.

He S, Liu Y, Ni C, Zhou Y, Li Y, Tang J. 3-6 Years Child Ho3-6 Years Child Home Nurture Environment Scale: development, reliability and validity. Chinese Journal of Child Health Care. 2009;17(02):134-6 + 139.

23.

Dai M, Lin L, Liang J, Wang Z, Jing J. Gender Difference in the Association Between Executive Function and Autistic Traits in Typically Developing Children. J Autism Dev Disord. 2019;49(3):1182-92.

24.

Wu X, Tao S, Rutayisire E, Chen Y, Huang K, Tao F. The relationship between screen time, nighttime sleep duration, and behavioural problems in preschool children in China. Eur Child Adolesc Psychiatry. 2017;26(5):541-8.

25.

Wang H, Li X, Li X. A Review of Research on Assessment Tool for Children with Autism in China. Chinese Journal of Special Education 2009(07):54-59+ 43.

26.

Zhang X, Ji C-Y. Autism and mental retardation of young children in China. Biomed Environ Sci. 2005;18(5):334-40.

27.

Ukoumunne OC, Wake M, Carlin J, Bavin EL, Lum J, Skeat J, Williams J, Conway L, Cini E, Reilly S. Profiles of language development in pre-school children: a longitudinal latent class analysis of data from the Early Language in Victoria Study. Child Care Health Dev. 2012;38(3):341-9.

28. 
Reilly S, Wake M, Ukoumunne OC, Bavin E, Prior M, Cini E, Conway L, Eadie P, Bretherton L. Predicting language outcomes at 4 years of age: findings from Early Language in Victoria Study. Pediatrics. 2010;126(6):e1530-7.

29.

Goh DA, Gan D, Kung J, Baron-Cohen S, Allison C, Chen H, Saw SM, Chong YS, Rajadurai VS, Tan KH, et al: Child, Maternal and Demographic Factors Influencing Caregiver-Reported Autistic Trait Symptomatology in Toddlers. 2018, 48(4):1325-1337.

30.

Dworzynski K, Ronald A, Hayiou-Thomas M, Rijsdijk F, Happe F, Bolton PF, Plomin R. Aetiological relationship between language performance and autistic-like traits in childhood: a twin study. International journal of language communication disorders. 2007;42(3):273-92.

31.

CW

Bartlett

$\mathrm{JF}$

Flax

MW

Logue

VJ

Vieland

AS

Bassett

$\mathrm{P}$

Tallal

LM

Brzustowicz

2002

Bartlett CW, Flax JF, Logue MW, Vieland VJ, Bassett AS, Tallal P, Brzustowicz LM: A major susceptibility locus for specific language impairment is located on 13q21. American journal of human genetics 2002, 71(1):45-55.

32.

$\mathrm{P}$

Warburton

G

Baird

W

Chen

$\mathrm{K}$

Morris

BW 
Jacobs

$\mathrm{S}$

Hodgson

Z

Docherty

2000

Warburton P, Baird G, Chen W, Morris K, Jacobs BW, Hodgson S, Docherty Z: Support for linkage of autism and specific language impairment to 7q3 from two chromosome rearrangements involving band $7 q 31$. American journal of medical genetics 2000, 96(2):228-234.

33.

Rohner RP. The parental "acceptance-rejection syndrome": universal correlates of perceived rejection. Am Psychol. 2004;59(8):830-40.

34.

M

Pinquart

2017

Pinquart M: Associations of parenting dimensions and styles with externalizing problems of children and adolescents: An updated meta-analysis. Developmental psychology 2017, 53(5):873-932.

35.

Waller R, Gardner F, Viding E, Shaw DS, Dishion TJ, Wilson MN, Hyde LW. Bidirectional associations between parental warmth, callous unemotional behavior, and behavior problems in high-risk preschoolers. J Abnorm Child Psychol. 2014;42(8):1275-85.

36.

Kochanska G, Kim S, Boldt LJ, Yoon JE. Children's callous-unemotional traits moderate links between their positive relationships with parents at preschool age and externalizing behavior problems at early school age. J Child Psychol Psychiatry Allied Discip. 2013;54(11):1251-60.

37.

Moricke E, Greven CU, Visser JC, Oosterling IJ, Buitelaar JK, Rommelse NNJ. Social-communicative and attention problems in infancy and toddlerhood as precursors of preschool autistic traits. 2019, 11(1):113-122.

38.

Evans GW, English K. The environment of poverty: multiple stressor exposure, psychophysiological stress, and socioemotional adjustment. Child development. 2002;73(4):1238-48.

39.

Conger RD, Donnellan MB. An interactionist perspective on the socioeconomic context of human development. Ann Rev Psychol. 2007;58:175-99.

40.

Ferguson KT, Cassells RC, MacAllister JW, Evans GW. The physical environment and child development: an international review. International journal of psychology: Journal international de psychologie. 2013;48(4):437-68. 
41.

Pervanidou P, Chrousos GP. Metabolic consequences of stress during childhood and adolescence. Metab Clin Exp. 2012;61(5):611-9.

42.

Keller PS, El-Sheikh M, Granger DA, Buckhalt JA. Interactions between salivary cortisol and alpha-amylase as predictors of children's cognitive functioning and academic performance. Physiol Behav. 2012;105(4):987-95.

43.

F

Hyseni

LME

Blanken

$\mathrm{R}$

Muetzel

FC

Verhulst

$\mathrm{H}$

Tiemeier

$\mathrm{T}$

White

2019

Hyseni F, Blanken LME, Muetzel R, Verhulst FC, Tiemeier H, White T: Autistic traits and neuropsychological performance in 6- to-10-year-old children: a population-based study. Child neuropsychology: a journal on normal and abnormal development in childhood and adolescence 2019, 25(3):352-369.

44.

Bralten J, van Hulzen KJ, Martens MB, Galesloot TE, Arias Vasquez A, Kiemeney LA, Buitelaar JK, Muntjewerff JW, Franke B. Autism spectrum disorders and autistic traits share genetics and biology. 2018, 23(5):1205-1212. 